UDC: 615.22:616.1:351.84

DOI: $10.15587 / 2519-4852.2021 .230028$

\title{
THE STRUCTURAL ANALYSIS OF GOVERNMENT EXPENDITURES ON THE PURCHASE OF ANTITUBERCULOUS DRUGS
}

\section{Iuliia Korzh, Tatyana Romanko, Alina Volkova, Lubov Tereschenko}

The aim. To conduct a structural analysis of the volume of government spending on the purchase of antituberculosis drugs (anti-TB D) within 2014-2018.

Materials and methods. In the study, we used information on public procurement of anti-TB D for 2014-2018 presented on the website of the Ministry of Health of Ukraine in the section "Procurement of Medicines", as well as statistical data of the "Center for Public Health of the Ministry of Health of Ukraine" on the incidence of multi-drug resistant tuberculosis (MDR-TB) in the population.

Analytical and comparative, system, and logical methods, as well as economic analysis were used. With the help of synthesis the conclusions and recommendations were formed.

Results. It was found that in 2014-2018, the MDR-TB incidence rate increase had a positive dynamics in reducing the number of registered cases. For example, in 2015 this indicator was $2.56 \%$, and in 2018 it was $-7.93 \%$.

It was proven that public procurement of anti-TB D in physical terms was chaotic. Thus, in 2015/2014, the growth rate of anti-TB D number was $35.55 \%$, in 2016/2015 - 31.59\%, in 2017/2016-15.31\%, in 2018/2017 - 6.13\%. It was found that the dynamics of the growth rate of purchases of TB D in the national currency and USD had some differences. For example, in 2015, expenses increased by $55.02 \%$ in the national currency, while in dollar terms this indicator decreased by $15.64 \%$ compared to 2014. At the same time, in 2018 there was a positive trend of increasing the volume of public spending in monetary terms. Thus, in 2018, the growth rate in the national currency was $53.16 \%$, and in USD - $49.83 \%$.

It was found that in the structure of public spending there was a tendency for an insignificant predominance of foreign anti-TB D. Based on the comparative analysis of government spending on groups of anti-TB D by the priority of their use in treatment regimens according to the standards it was determined that the process of anti-TB D purchasing did not meet the priority criteria for treatment. It complicates the implementation of the process of reforming TB care in connection with the construction of an outpatient model.

Conclusions. The results of the analysis indicate that there is a need to make a number of organizational and economic decisions to increase the level of availability of anti-TB D in the treatment of patients with MDR-TB. Critical measures include monitoring procurement programs based on real regional needs taking into account disease indicators. In addition, it is relevant to review the lists of drugs that are purchased with priority regarding the inclusion of drugs of domestic production, which belong to the second line anti-TB D in pharmacotherapy regimens. The list of measures also includes monitoring of prices taking into account inflationary processes in the state and predicting their impact on the volume of public spending on the purchase of anti-TB D

Keywords: multi-drug resistant tuberculosis, antituberculosis drugs, government expenditures, economic analysis, growth rates

How to cite:

Korzh, I., Romanko, T., Volkova, A., Tereschenko, L. (2021). The structural analysis of government expenditures on the purchase of antituberculous drugs. ScienceRise: Pharmaceutical Science, 2 (30), 17-25. doi: http://doi.org/10.15587/2519-4852.2021.230028

(C) The Author(s) 2021

This is an open access article under the Creative Commons CC BY license

\section{Introduction}

In Ukraine, the reform of the pharmaceutical sector in healthcare system has been identified as one of the main areas of the state policy aimed at developing effective mechanisms for providing the population with medicines in addition to affordable and effective pharmacotherapy, as well as the prevention of human diseases [1]. The implementation of various government programs aimed at increasing the level of accessibility of medical and pharmaceutical care to the population is impossible without analyzing the dynamics of changes in economic indicators of health development $[2,3]$.

In Ukraine, the concept of the National Target Program against tuberculosis (TB) for 2018-2021 has been approved. The goal of the Program is to stabilize the incidence rate, reduce mortality and increase the treatment effectiveness of patients. The concept provides the introduction of effective outpatient models of medical and pharmaceutical care, which are aimed at the patient-oriented approach. In this state program, it has been determined that a high level of prevalence rates of multi-drug resistant tuberculosis (MDR-TB) remains an urgent problem in the healthcare sector [4]. Thus, in 2018, Ukraine ranked 9th by the absolute number of MDR-TB cases revealed in the world. According to the WHO data, the effectiveness of the MDR-TB treatment is $34.9 \%[5,6]$.

MDR-TB leads to incapacitation, deterioration of human health, increased disability and mortality rates, indicating the presence of problems related to poverty and social inequality. This problem poses a 
threat to the national security of the country, and its solution requires a constant increase in expenditures from the state budget [7,8].

In Ukraine, the implementation of the state policy of controlling the prevalence of MDR-TB is based on the principles of providing universal and equal access of the population to high-quality services for prevention, diagnosis and treatment $[9,10]$. It should be noted that the implementation of these measures is carried out in two directions. The first direction is to improve the process of providing high-quality and effective medical and pharmaceutical care, and the second one is to increase the socio-economic availability of antituberculosis drugs (antiTB D) when treating patients with MDR-TB [11]. In Ukraine, the public procurement mechanism is used for uninterrupted and free provision of anti-TB D patients.
Analyzing the data of specialized literature it has been found that there are no studies concerning the volume of government expenditures on the purchase of anti-TB D in Ukraine. Taking this fact into account, as well as the socioeconomic importance of increasing the level of funding for providing pharmaceutical and medical care to patients with MDR-TB in conditions of a shortage of healthcare resources in Ukraine the following research aim has been formulated. Thus, the aim of our study was to conduct a structural analysis of the volume of government spending on the purchase of anti-TB D within 2014-2018.

\section{Planning (methodology) of research}

To achieve this aim, we have developed an algorithm for conducting the study, which consists of 5 stages (Fig. 1).

\begin{tabular}{|c|c|}
\hline $\begin{array}{c}\text { Stages of the } \\
\text { research }\end{array}$ & Characteristics of research stages \\
\hline \multirow[t]{2}{*}{ Stage I } & $\begin{array}{l}\text { Determination of the proportionality of anti-TB D purchases in relation to } \\
\text { MDR-TB morbidity rates }\end{array}$ \\
\hline & $\downarrow$ \\
\hline \multicolumn{2}{|c|}{$\begin{array}{l}\text { The analysis of the dynamics of the growth rate in the number of the MDR-TB cases } \\
\text { registered and the growth rate of the number of anti-TB D }\end{array}$} \\
\hline
\end{tabular}

\begin{tabular}{l}
\hline Stage II \\
$\begin{array}{l}\text { Determination of the volume of government expenditures on the purchase of } \\
\text { anti-TB D for 2014-2018 in monetary terms (in national currency and in US } \\
\text { dollars), including the price index }\end{array}$ \\
$\begin{array}{l}\text { The analysis of the dynamics of anti-TB D purchase costs for 2014-2018 in current (actual) } \\
\text { prices and comparable prices taking into account the inflation factor }\end{array}$ \\
\hline
\end{tabular}

\begin{tabular}{l}
\hline Stage III $\rightarrow \begin{array}{l}\text { Determination of the structure and dynamics of anti-TB D purchase costs for } \\
\text { 2014-2018 in terms of foreign and domestic production }\end{array}$ \\
$\begin{array}{l}\text { The ratio of government expenditure volumes for foreign and domestic anti-TB D. The } \\
\text { analysis of the dynamics of growth rates of anti-TB D purchase costs }\end{array}$
\end{tabular}

\begin{tabular}{|c|c|}
\hline Stage IV & $\begin{array}{l}\text { Identification of funding priorities for providing medical and pharmaceutical } \\
\text { care to patients with MDR-TB }\end{array}$ \\
\hline & $\downarrow$ \\
\hline \multicolumn{2}{|c|}{$\begin{array}{l}\text { The analysis of the procurement dynamics by groups of anti-TB D use in the treatment of } \\
\text { MDR-TB patients according to the standards }\end{array}$} \\
\hline Stage V & $\begin{array}{l}\text { Generalization of the research results for improving the financing of medical } \\
\text { and pharmaceutical care for patients with MDR-TB }\end{array}$ \\
\hline & $\frac{1}{1}$ \\
\hline
\end{tabular}

Fig. 1. The algorithm for analyzing the volume of government expenditures on the purchase of anti-TB D for 2014-2018 


\section{Materials and methods}

To conduct the study, we used information on public procurement of the second line anti-TB D for 2014-2018 presented on the website of the Ministry of Health of Ukraine in the section "Procurement of Medicines", as well as statistical data of the "Center for Public Health of the Ministry of Health of Ukraine" on the incidence of MDR-TB in the population [12].

Analytical and comparative, system, and logical methods, as well as economic analysis were used in the work. With the help of synthesis the conclusions and recommendations were formed. To determine the dynamics of indicators of public spending on the purchase of anti-TB D for 2014-2018, the growth rates were calculated (\%) [13]. The necessary data processing was performed using the standard statistical analysis packages - Statistica (version 12.0, StatSoft, Tulsa, USA) and Excel spreadsheet. significant.

The $p$-value $<0.05$ was considered as statistically

\section{Result}

In order to determine the availability of anti-TB D in MDR-TB patients in 2014-2018, an analysis of the dynamics of the growth rate of the number of registered MDR-TB cases and the purchase of anti-TB D in physical terms was performed. The results of the analysis are shown in Fig. 2.
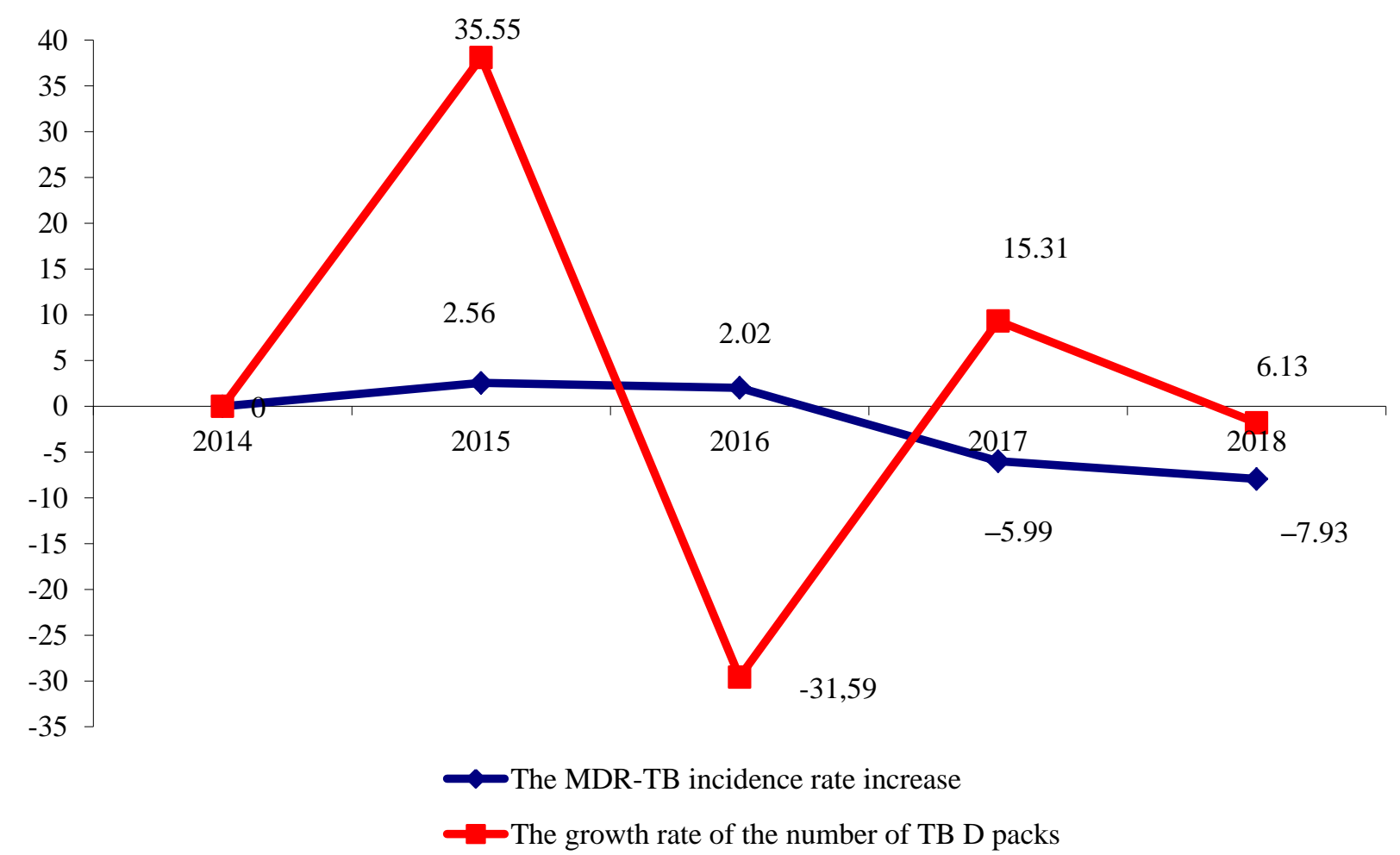

Fig. 2. The dynamics of the growth rate of the number of registered MDR-TB cases and the purchase of anti-TB D in physical terms in 2014-2018

It was found that in 2014-2018, the MDR-TB incidence rate increase had a positive dynamics in reducing the number of registered cases. For example, in 2015 this indicator was $2.56 \%$, and in 2018 it was $-7.93 \%$. This dynamics indicates a slow rate of decline in MDR-TB incidence indicators. We believe this should help to reduce the number of anti-TB D purchases. At the same time, the study proved that the purchase of anti-TB D in physical terms was chaotic. Thus, in 2015/2014, the growth rate of anti-TB D number was $35.55 \%$, in $2016 / 2015--31.59 \%$, in $2017 / 2016-15.31 \%$, in $2018 / 2017-6.13 \%$. In our opinion, a reduction in the purchase of anti-TB D packs by $31.59 \%$ in 2016 could lead to a discontinuation of the course of treatment, which was unacceptable in the treatment of MDR-TB patients. In our opinion, this situation may be due to unused drug residues with a long shelf life. According to the results of the study, it can be argued that the process of public procurement of the second line anti-TB D is unpredictable, and when forming the need for anti-TB D MDR-TB incidence rates are not taken into account.

Further, the volume of expenditures on anti-TB D was analyzed taking into account the price index for the period of 2014-2018. In the context of annual price growth (inflation), it is advisable to compare indicators of government spending volumes on anti-TB D in comparable prices taking into account the inflation factor. The study was conducted in the national currency and in US dollars at the exchange rate of the National Bank of Ukraine. In our opinion, in conditions of the rapid devaluation of the hryvnia, as well as the introduction of a $7 \%$ VAT rate on medicines from 01.04.2014, the analysis of the dynamics of changes in the volume of expenditures on anti-TB D in dollar terms is more indicative. The results are given in Fig. 3 and Fig. 4. 


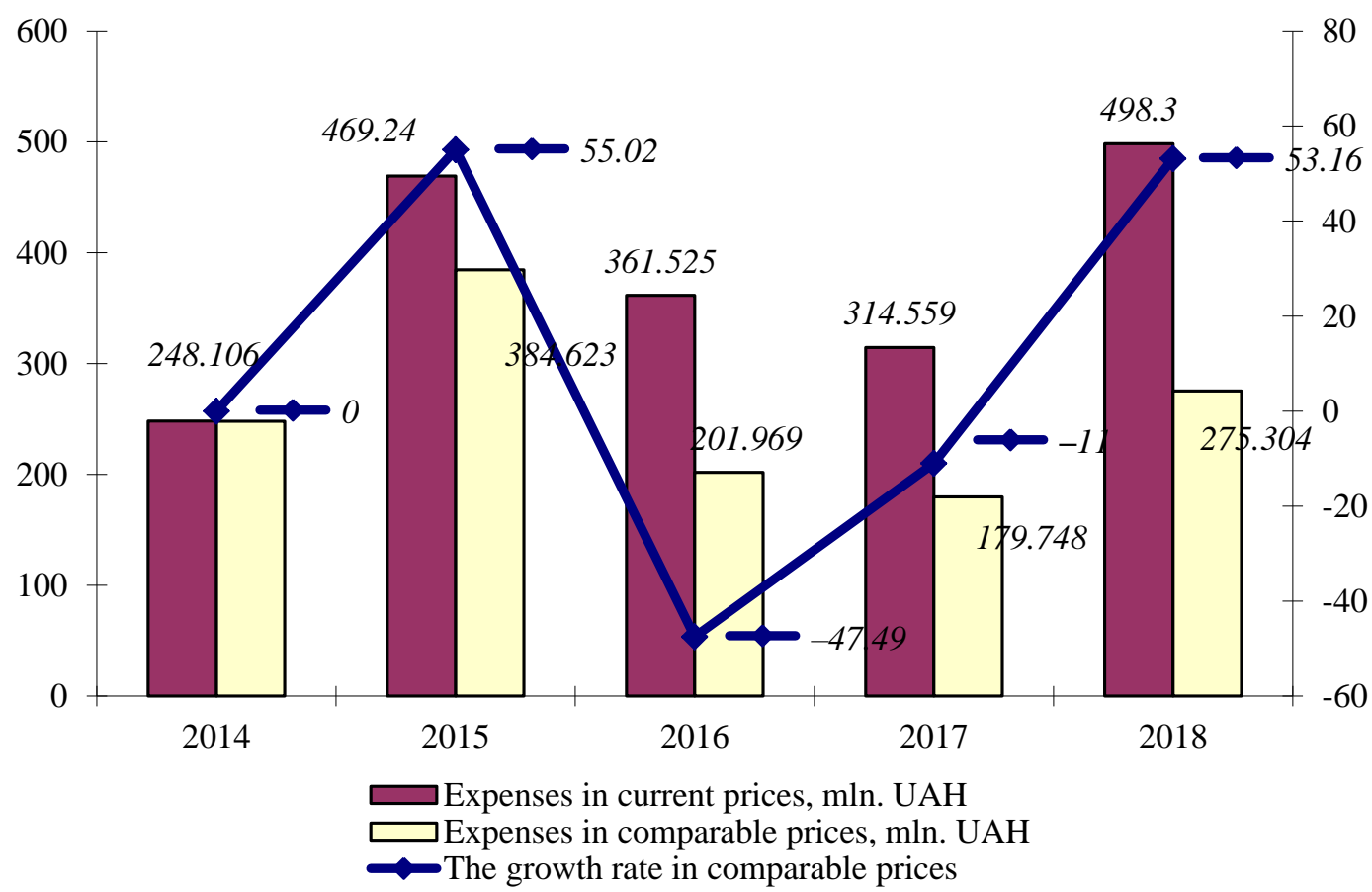

Fig. 3. The dynamics of government spending on the purchase of anti-TB D in the national currency for 2014-2018

Based on the results of the analysis it was found that the dynamics of the growth rate of purchases of anti-TB D in the national currency and USD had some differences. For example, in 2015, expenses increased by $55.02 \%$ in the national currency, while in dollar terms this indicator decreased by $15.64 \%$ compared to 2014. At the same time, taking into account the price index in 2016, the dynamics of government spending showed a decrease in the volume of expenditures in the national currency by $47.49 \%$, and in USD - by $55.09 \%$ compared to 2015 . In 2017, the growth rate of purchases decreased by $11 \%$ in UAH equivalent and by $14.55 \%$ in USD compared to 2016. It should be noted that in 2018 there was a positive trend of increasing the volume of public spending in monetary terms.

Thus, in 2018, the growth rate in the national currency was $53.16 \%$, and in USD $-49.83 \%$.

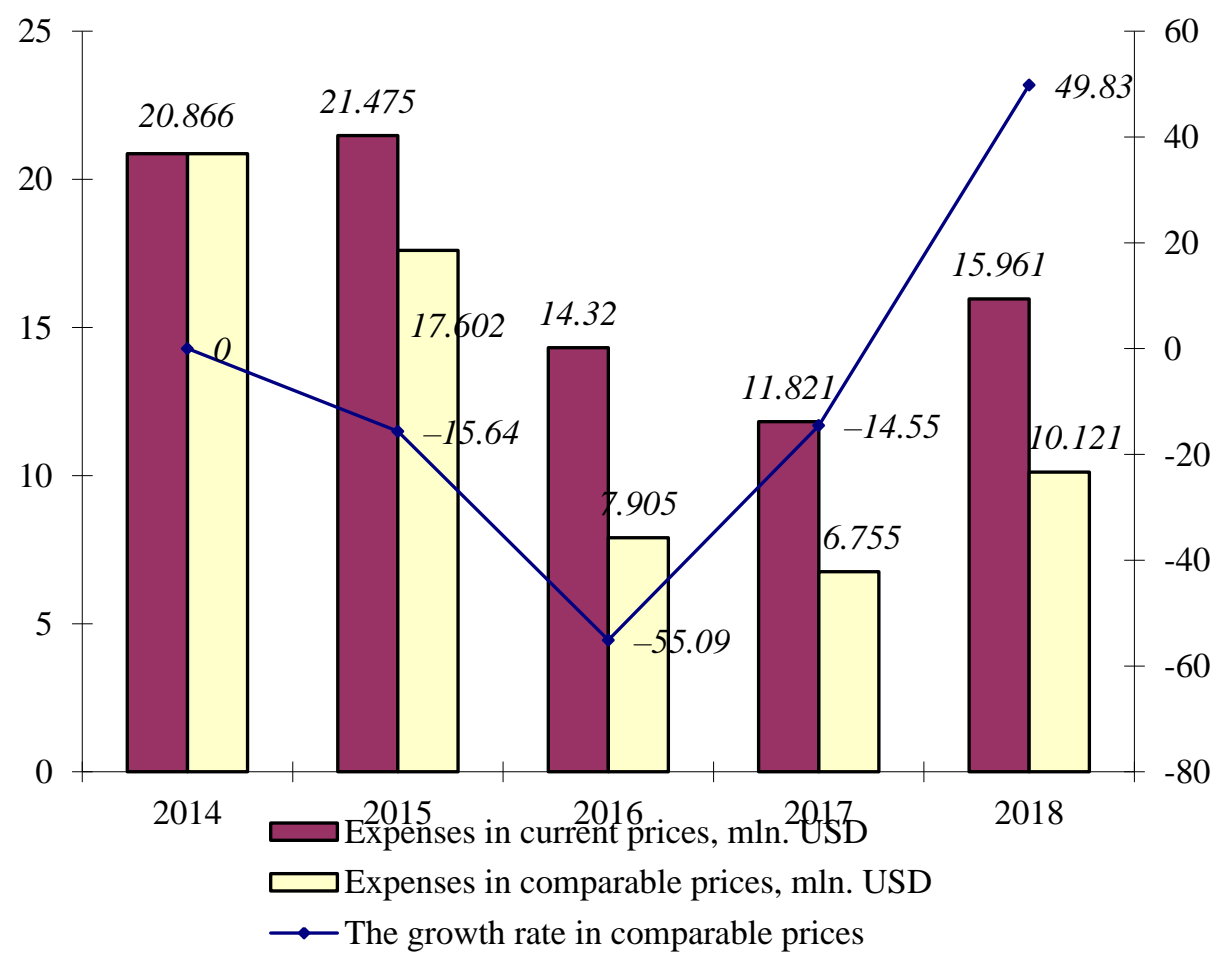

Fig. 4. The dynamics of government spending on the purchase of anti-TB D in US dollars 
Based on the results of the analysis, it can be argued that for the period 2014-2017 there were significant fluctuations in the volume of anti-TB D purchases. In our opinion, such significant fluctuations are associated with changes in macroeconomic indicators in the country, including fluctuations in the national currency, a decline in production and so on. In addition, it should be noted that in the period from 2014 to 2017, an electronic procedure for the purchase of drugs through the "Prozorro" system was introduced, which could also cause fluctuations in the procurement system of anti-TB D. However, the procurement process streamlining in 2018 can be considered positive.

The next stage of the study was the analysis of the structure of public procurement volumes of anti-TB D in the context of domestic and foreign production (Fig. 5). Based on the obtained data, it can be argued that during
2014-2017 there was a tendency for an insignificant predominance of foreign anti-TB D. At the same time, the results of the analysis of government spending in 2018 showed a positive trend towards an increase in the share of domestic anti-TB D. Thus, in 2018, the share of government expenditures on the purchase of domestic anti-TB D was $52 \%$.

Next we analyzed the growth rate of purchase costs on anti-TB D in the context of domestic and foreign production (Fig. 6). It was found that the dynamics of fluctuations in the cost of purchasing anti-TB D of domestic production had a negative value only in 2016 (-11.84\%) compared to 2015.

The indicators of the growth rate of purchases of foreign anti-TB D demonstrated uneven dynamics. In 2018, anti-TB D purchase costs increased by $89.47 \%$ compared to 2017.
2018

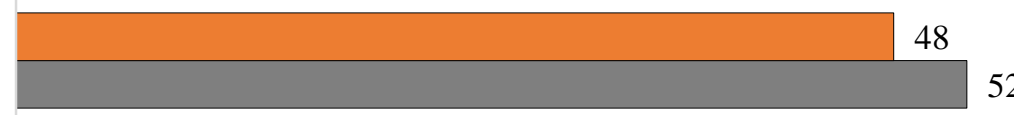

2017

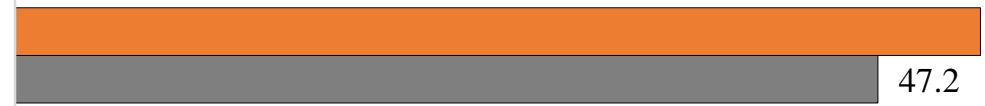

2016

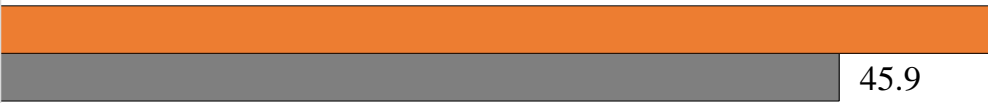

54.1

2015

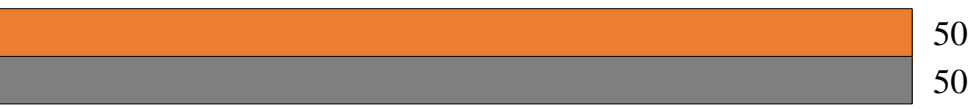

2014

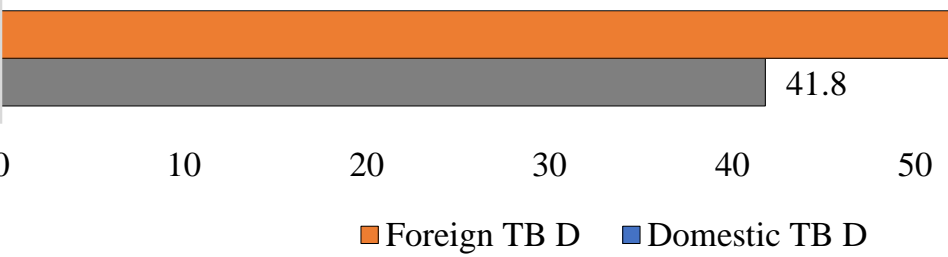

58.2

Foreign TB D Domestic TB D

Fig. 5. The analysis of government spending on purchases of anti-TB D in the context of domestic and foreign production, $\%$

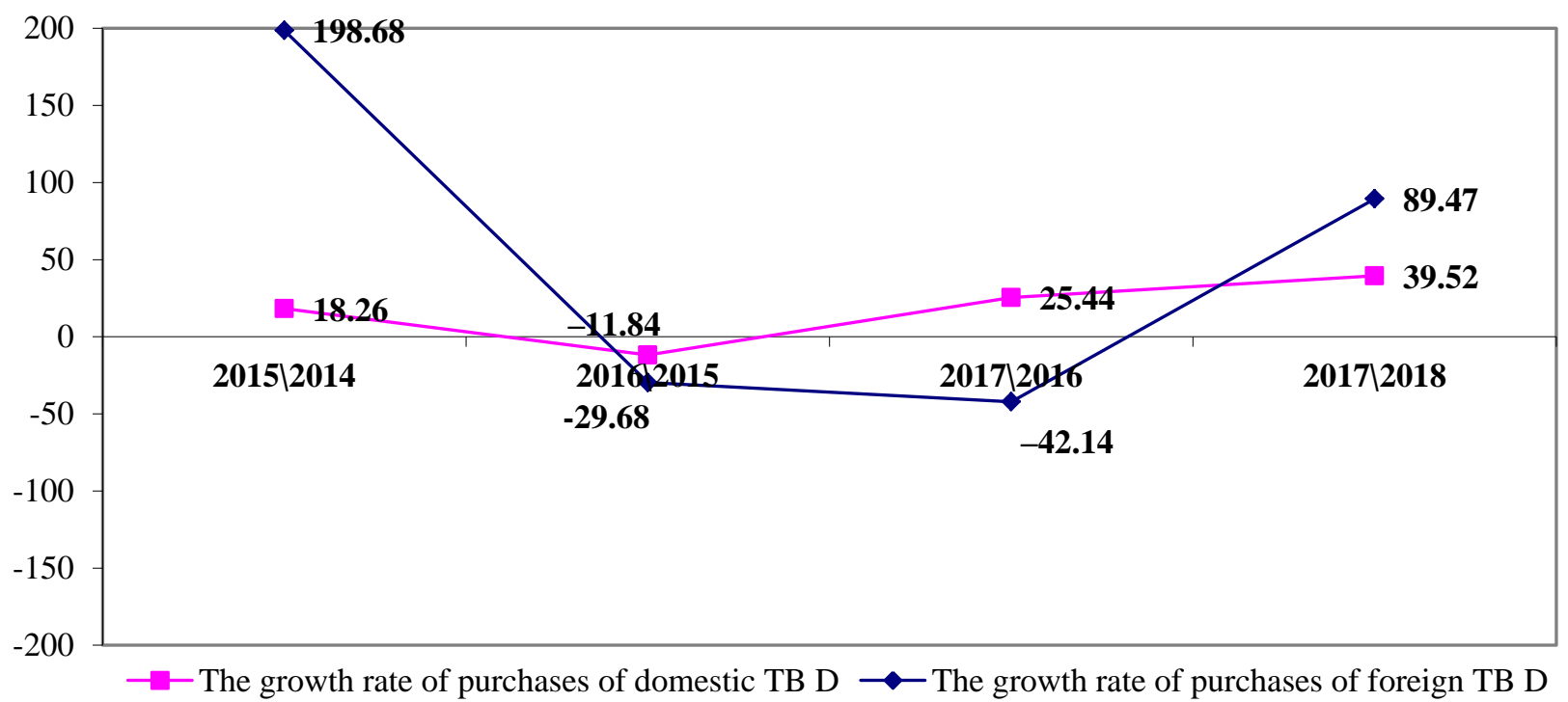

Fig. 6. The dynamics of growth rates of purchase costs on anti-TB D in the context of domestic and foreign production 
In order to determine the distribution of government spending on pharmaceutical care for MDRTB patients, anti-TB D public procurement data by pharmacotherapy groups were analyzed. According to the order of the Ministry of Health of Ukraine dated 25.02.2020 No. 530 "On approval of health standards for tuberculosis", it has been determined that MDR-TB pharmacotherapy regimens are divided into three groups. Thus, Group A (highly-effective anti-TB D) includes fluoroquinolones (levofloxacin and moxifloxacin), bedaquiline and linezolid. Group B (additional anti-TB D) clofazimine, cycloserine or terizidone are recommended as second-choice drugs. Group $\mathrm{C}$ drugs (auxiliary antiTB D) are used if it is impossible to apply medicines from the first and second groups. Other drugs are not recommended for use [14].
Based on the results of the analysis, it was found that the volume of purchasing costs in Group A (highlyeffective TB D) in 2015, 2017, and 2018 tended to grow (Table 1). At the same time, in 2016, expenditures decreased by $20.79 \%$ compared to 2015 . In our opinion, the reduction in public spending on the purchase of antiTB D for Group A contradicts the approaches to providing pharmaceutical care to patients with MDR-TB in accordance with the treatment standards. It should be noted that the innovative anti-TB $\mathrm{D}$ bedaquiline recommended since 2013 by the WHO for the treatment of MDR-TB $[15,16]$ was registered in Ukraine only in 2018. This fact explains the absence of this anti-TB D in public procurement.

Table 1

The dynamics of growth rates of purchase costs on anti-TB D by INN, \%

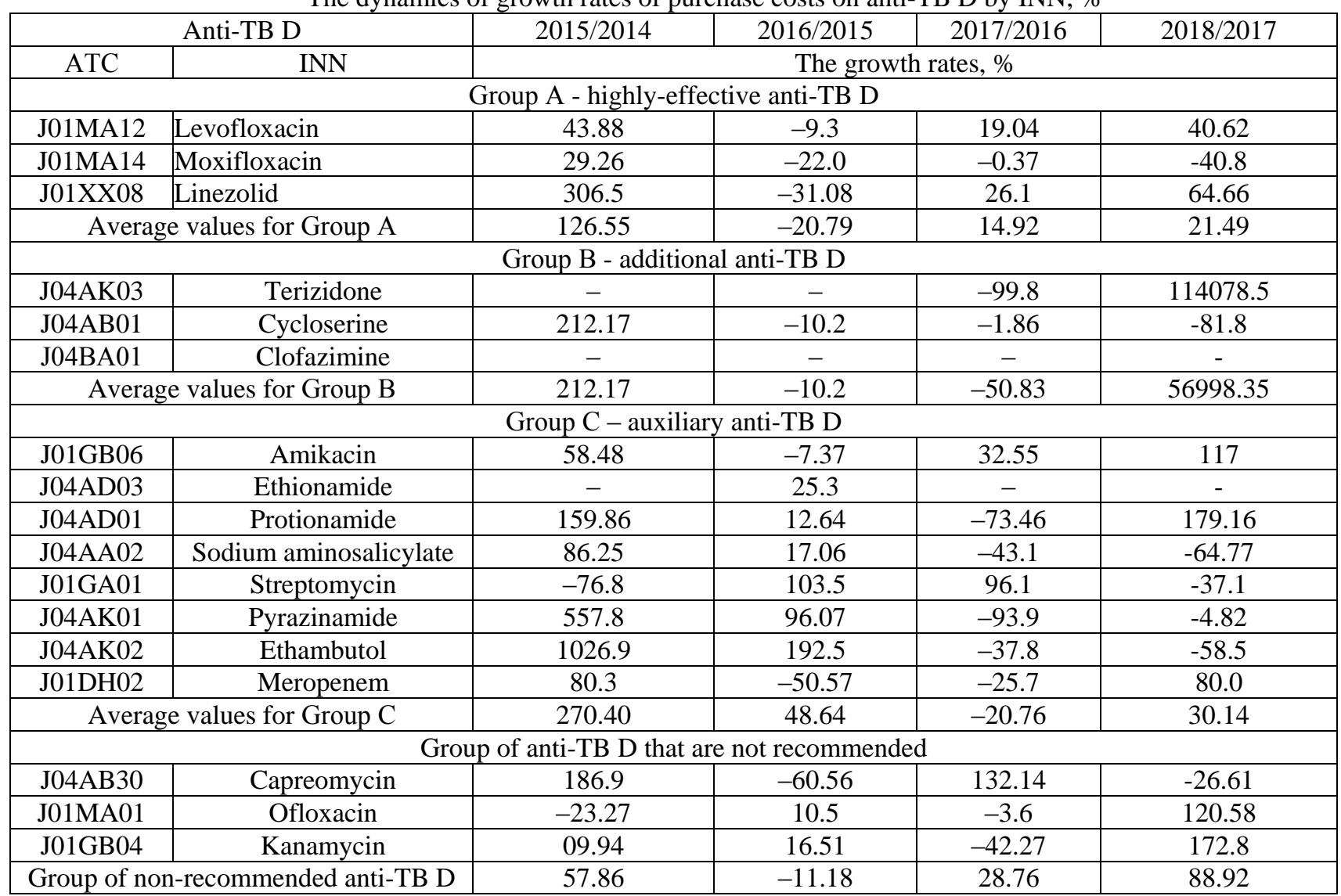

The analysis of Group B (additional anti-TB D) shows that the indicators of the growth rate of government spending on anti-TB D purchasing tend to increase. For example, in 2015, the volume of expenditures increased by $212.17 \%$ compared to 2014 , and in 2018 - by $56998.4 \%$ compared to 2017 . It is interesting that in 2018 it was for anti-TB D of Group B that the trend of the greatest growth in government spending was observed. Thus, in 2018, the volume of expenditures on the purchase of terizidone increased by 114078.5 \% compared to 2017. In our opinion, this increase in procurement volumes is due to the fact that these anti-TB D, according to the WHO Consolidated Guidelines, have been included in Group B and recommended for use in MDR-TB treatment schemes as a priority. In addition, this situation can be justified by the fact that the drug terizidone has the lowest price range among the drugs of group $B$, which led to the replacement of other drugs in this group. This dynamic does not correspond to the rational use of public funds and confirms the fact that when forming anti-TB D purchases the need is not the basic norm when planning purchases. It was determined that for Group C, there was a tendency to increase the volume of government spending on anti-TB D purchases, the exception was 2017. For example, in 2017, the state spent $20.76 \%$ less money on anti-TB D purchases than in 2016. Special attention should be paid to data on the purchase of anti- 
TB D, which are not recommended for use according to the treatment standards. Thus, the calculated growth rate indicators show that in 2015, 2017, and 2018, there was a tendency to increase the volume of expenses for purchases of non-recommended anti-TB D.

Based on the results of the analysis, it can be argued that the process of purchasing anti-TB D for the period of 2014-2018 does not meet the priority criteria for the MDR-TB treatment and complicates the implementation of the process of reforming anti-TB care for patients. This process aims at a gradual, but confident transition to an outpatient treatment model, and as a result, it provides for $100 \%$ availability of all anti-TB D, introduction of a greater number of combined drugs into the treatment process and refusal of injectable anti-TB D.

\section{Discussion}

Systematizing the results of studying the indicators of public spending on the purchase of the second line anti-TB D for treating MDR-TB for 20142018 the following conclusions can be made. First, the procurement process of the second line anti-TB D in physical terms was independent of the number of MDRTB cases reported. This makes it impossible to use them due to their expiration date and the need for disposal. This fact proves that in conditions of the lack of funding, there is a risk of non-fulfillment of state guarantees for the implementation of medical and pharmaceutical care for MDR-TB patients. We think there is an urgent need to review the collection of data from healthcare institutions regarding their need for the second line antiTB D taking into account the projected proportion of undetected MDR-TB cases.

Secondly, the analysis of the second line anti-TB $\mathrm{D}$ procurement costs, taking into account the price index for the period 2014-2018, showed that the crisis processes occurred in 2015-2017 in the financial market of Ukraine, and the introduction of measures by the state that led to an increase in drug prices, had a direct impact on the volume of anti-TB D procurement costs. To our mind, this indicates that when planning the need for purchasing anti-TB D it is necessary to take into account inflationary processes.

Third, the analysis of the structure of public procurement volumes of anti-TB D in the context of domestic and foreign production for 2014-2018 has demonstrated that when purchasing foreign anti-TB D are the priority. In our opinion, this trend makes it necessary to review the existing tender procurement procedure with priority given to anti-TB D of domestic production on condition of bioequivalence confirmation and the presence of a declared wholesale and selling price.

It has been found that the structure of anti-TB D procurement volumes by nomenclature does not correspond to the priorities of the MDR-TB pharmacotherapy. There is an increase in the volume of purchases of anti-TB D, which are not recommended in the treatment of MDR-TB. It is also necessary to note that there is disproportionality of purchases for individual INN, which growth rate exceeds $1000 \%$. It has been proven that there is a reduction in the pace of purchases of priority anti-TB D.
The results of the obtained study allow us to form a more rational financial policy, which ultimately creates favorable conditions for the right of a patient with MDRTB to receive free and high-quality pharmaceutical and medical care. At the same time, they can only be used when making organizational and economic decisions to improve the provision of the second line anti-TB D for MDR-TB patients.

When developing rational models for financing the provision of medical and pharmaceutical care to patients with MDR-TB the following areas of prospective research were identified: conducting a detailed factor analysis of the influence of external and internal parameters on the dynamics of changes in public spending indicators for the second line anti-TB D; studying the distribution of procurement volumes for the second line anti-TB D in accordance with the administrative-territorial division of the country, as well as infrastructure opportunities, from a medical and pharmaceutical point of view, for the development of its individual areas.

Studies of the state of drug supply of patients with TB were conducted by Ukrainian scientists. Based on the correlation-regression analysis, scientists have developed a method for assessing the factors influencing the level of TB incidence and identified those of them that are the main causal determinants of the overall situation regarding the development of morbidity. It is proved that taking into account the regional features of differentiated and cumulative influence of these factors on the situation with TB is a necessary step and a guarantee of reliability of prognostic assessment of morbidity and determining the need for anti-TB D in the near future [17]. In addition, Ukrainian scientists have proposed recommendations for developing a scale of levels of impact on the budget when assessing the purchase of drugs in Ukraine. Based on the analysis of procurement of drugs from the National List and central programs, the authors updated the recommendations on the scale of levels of impact on the budget according to 2019 in Ukraine and identified two scenarios, depending on the level of procurement and regulatory list. The scale is recommended for use in the assessment of medical technologies and as an auxiliary tool for the decision-making process on the inclusion of new drugs in regulatory lists in Ukraine [18]. The problematic issues of the pharmaceutical component of the nationwide targeted social program to combat tuberculosis for 2012-2016 are considered.

Study limitations. The obtained results of the research allow to form a more rational financial policy, which ultimately creates favourable conditions for the realization of the patient's right to MDR-TB to receive free and quality pharmaceutical and medical care. However, they can be used only in organizational and economic decisions to improve the provision of anti-TB D II in a number of patients with MDR-TB.

Prospects for further research. In developing rational models of financing the provision of medical and pharmaceutical care to patients with MDR-TB, we have identified the following areas of future research: conducting a detailed factor analysis of the impact of external and internal parameters on the dynamics of changes in government spending on anti-TB D II series; study of the 
distribution of procurement volumes on anti-TB D II series in accordance with the regions of the country. In our opinion, a promising vector of the study will be modelling the impact of socio-economic determinants on the prevalence of TB and determining the cause-and-effect relationships of socio-economic status and socioeconomic determinants of $\mathrm{TB}$, conducted by foreign scientists $[19,20]$.

\section{Conclusions}

The results of the analysis of government spending on the purchase of anti-TB D II series for the treatment of MDR-TB for 2014-2018 show that there is a need for a number of organizational and economic decisions to increase the availability of anti-TB D in the treatment of patients with MDR-TB. It is proved that the process of purchasing anti-TB D series in kind is carried out without taking into account the indicators of the number of registered cases of MLS-TB. It is established that the crisis processes that took place in 2015-2017 in the financial market of Ukraine led to an increase in drug prices and had an impact on the cost of purchasing antiTB D. The results show that in determining the need for
anti-TB D it is necessary to monitor prices taking into account inflationary processes in the country and forecasting their impact on government spending on anti-TB $\mathrm{D}$ procurement. Analysis of the structure of public procurement of anti-TB D in terms of domestic and foreign production showed a trend of anti-TB D foreign production. It is proved that the structure of anti-TB D procurement volumes by nomenclature does not correspond to the priorities of MDR-TB pharmacotherapy. Thus, there is a tendency to reduce the rate of procurement on the priority anti-TB D. Thus, the results of the study can be used in the development of scientific and applied approaches to the organization of effective financing in the provision of pharmaceutical care in Ukraine.

Thus, the results of the study can be used in the development of scientific and applied approaches to the organization of effective financing when providing pharmaceutical care in Ukraine.

\section{Conflict of interests.}

The authors declare that they have no conflicts of interest.

\section{References}

1. Kotvitska, A., Prokopenko, O. (2020). Determination of social and economic accessibility of drugs for treatment of Parkinson's disease on the basis of modern approaches. Pharmacia, 67 (3), 173-179. doi: http://doi.org/10.3897/pharmacia.67.e46586

2. Samborskyi, O., Slobodyanyuk, M., Panfilova, H. (2020). Comparative analysis of the dynamics of healthcare expenditures from country GDP and cash payments of families to medical and pharmaceutical support in Ukraine, CIS countries and EU. ScienceRise: Pharmaceutical Science, 3 (25), 20-27. doi: http://doi.org/10.15587/2519-4852.2020.206569

3. .Pakdaman, M., Geravandi, S., Askari, R., Askarishahi, M., Afzali, R. H. (2019). The effect of macroeconomic indica-tors on health-care expenditure in Iran. Journal of Education and Health Promotion, 8 (1), 123.

4. Pro skhvalennia Kontseptsii Zahalnoderzhavnoi tsilovoi sotsialnoi prohramy protydii zakhvoriuvanniu na tuberkuloz na 2018-2021 roky (2017). Rozporiadzhennia Kabinetu Ministriv Ukrainy No. 1011-r. 27.12.2017. Available at: https://zakon.rada.gov.ua/laws/show/10112017- \%D1 \%80\#Text

5. World Health Organization. Regional Office for Europe. (2019). Tuberculosis surveillance and monitoring in Europe 2019: 2017 data. Available from: https://apps.who.int/iris/handle/10665/311349

6. Tuberculosis (2020). World Health Organization: WHO. Available at: https://www.who.int/news-room/factsheets/detail/tuberculosis

7. Mase, S., Chorba, T., Parks, S., Belanger, A., Dworkin, F., Seaworth, B. et. al. (2019). Bedaquiline for the Treatment of Multidrug-resistant Tuberculosis in the United States. Clinical Infectious Diseases, 71 (4), 1010-1016. doi: http://doi.org/10.1093/cid/ciz914

8. Lange, C., Aarnoutse, R. E., Alffenaar, J. W. C., Bothamley, G., Brinkmann, F., Costa, J. et. al. (2019). Management of patients with multidrug-resistant tuberculosis. The International Journal of Tuberculosis and Lung Disease, 23 (6), 645-662. doi: http://doi.org/10.5588/ijtld.18.0622

9. Feshchenko, Yu. I., Melnyk, V. M., Turchenko, L. V. (2015). A concept of reformation of tuberculosis healthcare system and optimization of anti-tuberculosis activity in Ukraine (project). Ukrainskyi pulmonolohichnyi zhurnal, 1 (87), 5-9.

10. Feshchenko, Y. I. (2019). Up-to-date tendencies in tuberculosis research. Ukrainian Pulmonology Journal, 1, 8-24. doi: http://doi.org/10.31215/2306-4927-2019-103-1-8-24

11. Feshchenko, Y. I., Lytvynenko, N. A., Varytska, H. O., Chobotar, O. P., Pohrebna, M. V., Senko, Y. O. et. al. (2017). Prospects for improving the treatment efficacy for patients with multidrug resistant tuberculosis: global trends and national advances. Infectious Diseases, 4, 10-21. doi: http://doi.org/10.11603/1681-2727.2017.4.8418

12. Tsentr hromadskoho zdorovia MOZ Ukrainy. Available at: https://phc.org.ua

13. Feshchur, R. V., Barvinskyi, A. F., Kichor, V. P. (2003). Statystyka: teoretychni zasady i prykladni aspekty. Lviv: Intelekt-Zakhid, 576.

14. Pro zatverdzhennia standartiv okhorony zdorovia pry tuberkulozi (2020). Nakaz MOZ Ukrainy No. 530. 25.02.2020. Available t: https://phc.org.ua/sites/default/files/users/user90/Nakaz_MOZ_vid_25.02.2020_530_Standarty_medopomogy_pry_TB.pdf

15. Zvedena nastanova VOOZ z tuberkulozu. Modul 4: likuvannia Likuvannia likarsko-stiikoho tuberkulozu. Available at: https://phc.org.ua/sites/default/files/users/user90/WHO \%20consolidated \%20guidelines \%20on \%20tuberculosis \%20Module \%204 $\% 20$ Treatment \%20Drug-resistant \%20tuberculosis \%20treatment_UKR.pdf

16. Global tuberculosis report 2018 (2018). Geneva: World Health Organization. Available at: https://apps.who.int/iris/ bitstream/handle/10665/274453/9789241565646-eng.pdf 
17. Sadova, D. T., Hrom O. L. (2009). Klasternyi analiz vplyvu medychnykh, demohrafichnykh ta sotsialno-ekonomichnykh chynnykiv na zakhvoriuvanist tuberkulozom. Farmatsevtychnyi chasopys, 2, 53-56.

18. Oleshchuk, O. M., Piniazhko, O. B., Kovtun, L. I., Serediuk, V. V., Masheiko, A. M., Topachevskyi, O. A. (2020). Update of recommendations concerning development of the scale of budget impact rate in the evaluation of the purchase of medicines in Ukraine as for 2019 data. Pharmaceutical Review, 2, 76-83. doi: http://doi.org/10.11603/2312-0967.2020.2.11256

19. Prilipko, N. A. (2014). Problematic issues of the pharmaceutical component of the national target social program to combat the incidence of tuberculosis for 2012-2016. Pharmaceutical Review, 3, 71-74.

20. Pedrazzoli, D., Boccia, D., Dodd, P. J., Lönnroth, K., Dowdy, D. W., Siroka, A. et. al. (2017). Modelling the social and structural determinants of tuberculosis: opportunities and challenges. The International Journal of Tuberculosis and Lung Disease, 21 (9), 957-964. doi: http://doi.org/10.5588/ijtld.16.0906

Received date 16.03.2021

Accepted date 22.04.2021

Published date 30.04.2021

Iuliia Korzh, PhD, Associate Professor, Department of Social Pharmacy, National University of Pharmacy, Pushkinska str., 53, Kharkiv, Ukraine, 61002

E-mail: socpharm@ nuph.edu.ua

Tatyana Romanko, Assistant, Department of Social Pharmacy, National University of Pharmacy, Pushkinska str., 53, Kharkiv, Ukraine, 61002

E-mail: socpharm@ nuph.edu.ua

Alina Volkova, PhD, Associate Professor, Department of Social Pharmacy, National University of Pharmacy, Pushkinska str., 53, Kharkiv, Ukraine, 61002

E-mail: socpharm@ nuph.edu.ua

Lubov Tereshchenko, PhD, Associate Professor, Department of Social Pharmacy, National University of Pharmacy, Pushkinska str., 53, Kharkiv, Ukraine, 61002

E-mail: socpharm@nuph.edu.ua 